NOUVELLE

\title{
Propagation rapide de cellule en cellule
}

\section{Les virus ne manquent pas de ressort}

Virginie Doceul, Adrien Breiman, Mike Hollinshead, Geoffrey L. Smith

\section{Plages de lyse induites par l'infection virale}

II y a plus de 50 ans, Dulbecco mettait en évidence la formation de plages de lyse en réponse à l'inoculation de cultures cellulaires uniformes avec des virus d'origine animale [1]. Cette découverte repose sur le principe selon lequel une seule particule virale est capable d'infecter une cellule, de se répliquer et ensuite de libérer de nouveaux virions qui infecteront les cellules voisines. Un nouveau cycle de réplication aboutit à la libération de nouveaux virions et à l'infection des cellules adjacentes. Lorsque l'infection a des effets cytopathiques et entraîne la mort cellulaire, ce qui est le cas pour de nombreux virus, un foyer de lyse cellulaire se forme. Celui-ci peut être visible à l'œil nu après plusieurs jours d'infection. L'aptitude de tels virus à former une plage de lyse à partir d'une seule particule virale est à la base des tests de titration et a conduit à de nombreux progrès dans le domaine de la virologie. Dans son étude, Dulbecco décrivait la formation de plages de lyse de 2 à $4 \mathrm{~mm}$ de diamètre dans des cultures de fibroblastes d'embryon de poulet infectées avec le virus de l'encéphalite équine de l'ouest (WEE) [1]. De nombreux autres virus forment des plaques de diamètre similaire. C'est le cas du virus de la vaccine (VACV), un virus à ADN double brin, membre du genre Orthopoxvirus de la famille des Poxviridae, qui a permis l'éradication de la variole [2]. Ce virus est capable de former des plages de lyse de 2 à 3 millimètres après 3 jours d'infection (Figure 1-A) [3]. D'autres exemples incluent le virus herpes simplex (HSV) ou le virus de la grippe [4, 5]. La cinétique de réplication du virus et le temps nécessaire à la production et à l'excrétion de nouveaux virions ont longtemps été considérés comme les facteurs limitant la vitesse de formation des plages de lyse. Cependant, jusqu'à récemment, aucune étude n'avait été réalisée qui puisse confirmer ou réfuter cette hypothèse.

\section{Le virus de la vaccine et sa vitesse de propagation de cellule en cellule} Les progrès réalisés dans le domaine de la microscopie permettent aujourd'hui de visualiser en temps réel des cellules vivantes pendant plusieurs jours. II est alors possible d'enregistrer la cinétique de formation de plages de lyse. Grâce à cette stratégie, notre équipe a récemment démontré que le virus VACV se propage d'une cellule à une autre en seulement 1,2 heure [3]. Or, l'étude du cycle infectieux du virus a montré qu'il faut environ 6 heures entre l'infection d'une cellule et la production des premiers virions dans le milieu extracellulaire [6]. Le VACV se propagerait donc quatre fois plus rapidement que sa cinétique de réplication ne le laisserait supposer. Différents mécanismes facilitant la propagation du virus de cellules en cellules ont été rapportés $(\rightarrow)$.

L'un d'entre eux est la formation de comètes d'actine suivant

$(\rightarrow)$ Voir la Nouvelle de M.I. Thoulouze et A. Alcover, page 571 de ce numéro la sortie hors de la cellule de nouveaux virions (Figure 1b) [7]. Ces projections poussent le virus vers les cellules voisi-
Section of Virology, Faculty of Medicine, Imperial College London, St Mary's Campus, Norfolk Place, Londres W2 IPG, Royaume-Uni. v.doceul@imperial.ac.uk

nes, facilitant l'infection de ces dernières [8]. Un accroissement de la motilité cellulaire six heures après infection a aussi été décrit, qui faciliterait la migration des cellules infectées vers les cellules saines [9]. Ces mécanismes, induits par le virus pour faciliter sa propagation entre cellules, interviennent cependant à un stade assez avancé de l'infection ou sont contemporains de la sortie de nouveaux virions; ils ne peuvent donc pas expliquer la transmission du VACV d'une cellule à une autre en moins de deux heures. Quelle ruse a donc trouvé le virus?

\section{Le mécanisme}

\section{de propagation rapide de VACV}

L'examen microscopique répété de la périphérie de plages de lyse formées par VACV et l'enregistrement de vidéos ont montré que des cellules infectées ne produisant pas de nouvelles particules virales ou ne possédant pas d'《usines à virus» (structures cytoplasmiques où la réplication du génome viral se produit), peuvent organiser des comètes d'actine et repousser un virion contactant leur surface. De plus, nous avons fait une observation surprenante: plusieurs comètes d'actine se forment successivement à la surface d'une même cellule au contact du même virion qui rebondit alors à la surface de la cellule fraîchement infectée [3]. Les cellules infectées par VACV sont donc capables de générer des comètes d'actine très tôt après leur infection, avant que de nouvelles particules virales ne se forment. Deux protéines virales sont responsables de ce mécanisme: $A 33$ et $A 36$. Ces deux protéines exprimées très tôt après infection $[10,11]$ sont localisées au niveau de la membrane plasmique $[12,13]$ et interagissent l'une 

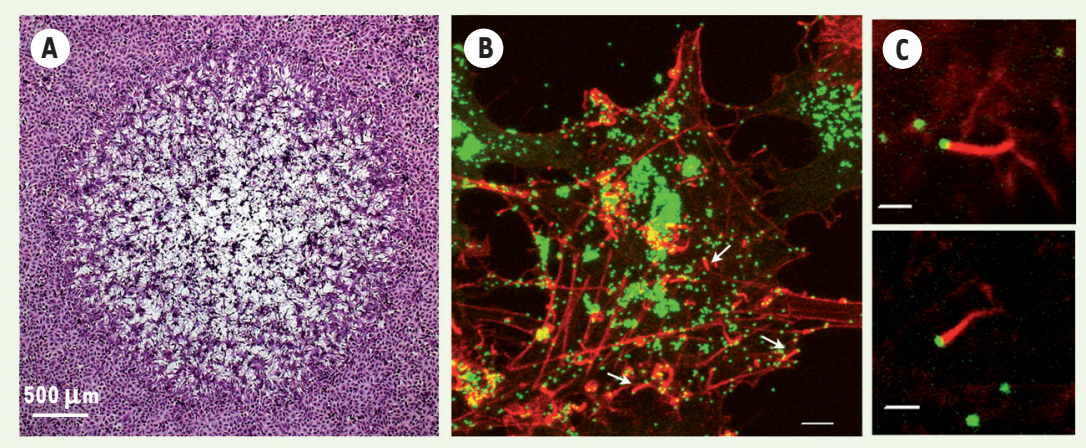

Figure 1. La plage de lyse et les comètes d'actine induites par VACV. A. Plage de lyse formée par VACV dans une couche uniforme de cellules de rein de singe vert d'Afrique après coloration au cristal violet. Barre $=500 \mu \mathrm{m}$. B. Une cellule infectée par une souche de VACV exprimant la protéine virale $A 5$ conjuguée à la protéine fluorescente verte (GFP) génère des comètes d'actine (rouge) suivant la sortie de virions (points verts) dans le milieu extracellulaire. Quelques exemples de comètes d'actine sont indiqués par des flèches blanches. Barre $=5 \mu \mathrm{m}$. C. Des comètes d'actine (rouge) détectées dans des cellules exprimant les protéines virales $\mathrm{A} 33$ et A36 après addition à leur surface de particules virales produites par VACV (points verts). Barre $=2 \mu \mathrm{m}$.

avec l'autre [14]. Des virus mutants par suppression ou troncation de l'une ou l'autre de ces protéines sont incapables d'induire la formation de comètes d'actine, génèrent des plages de lyse de taille très réduite et ont une virulence atténuée in vivo $[10,11,15]$. De façon remarquable, l'expression d'A33 et d'A36 dans des cellules non infectées est nécessaire et suffisante à la formation de comètes d'actine après addition de particules virales à leur surface (Figure 1-c) [3]. De plus, l'expression d'A33 et d'A36 très tôt après infection par VACV est essentielle à la propagation optimale du virus en culture cellulaire [3]. Ces différentes données ont permis l'élaboration du modèle de propagation rapide de VACV par répulsion qu'illustre la Figure 2. Très tôt après infection par VACV, A33 et A36 sont exprimées au niveau de la membrane plasmique et provoquent la formation de comètes d'actine au contact de virions présents dans le milieu extracellulaire. Ces particules virales sont alors projetées vers les cellules voisines. S'il rencontre une cellule déjà infectée et exprimant le

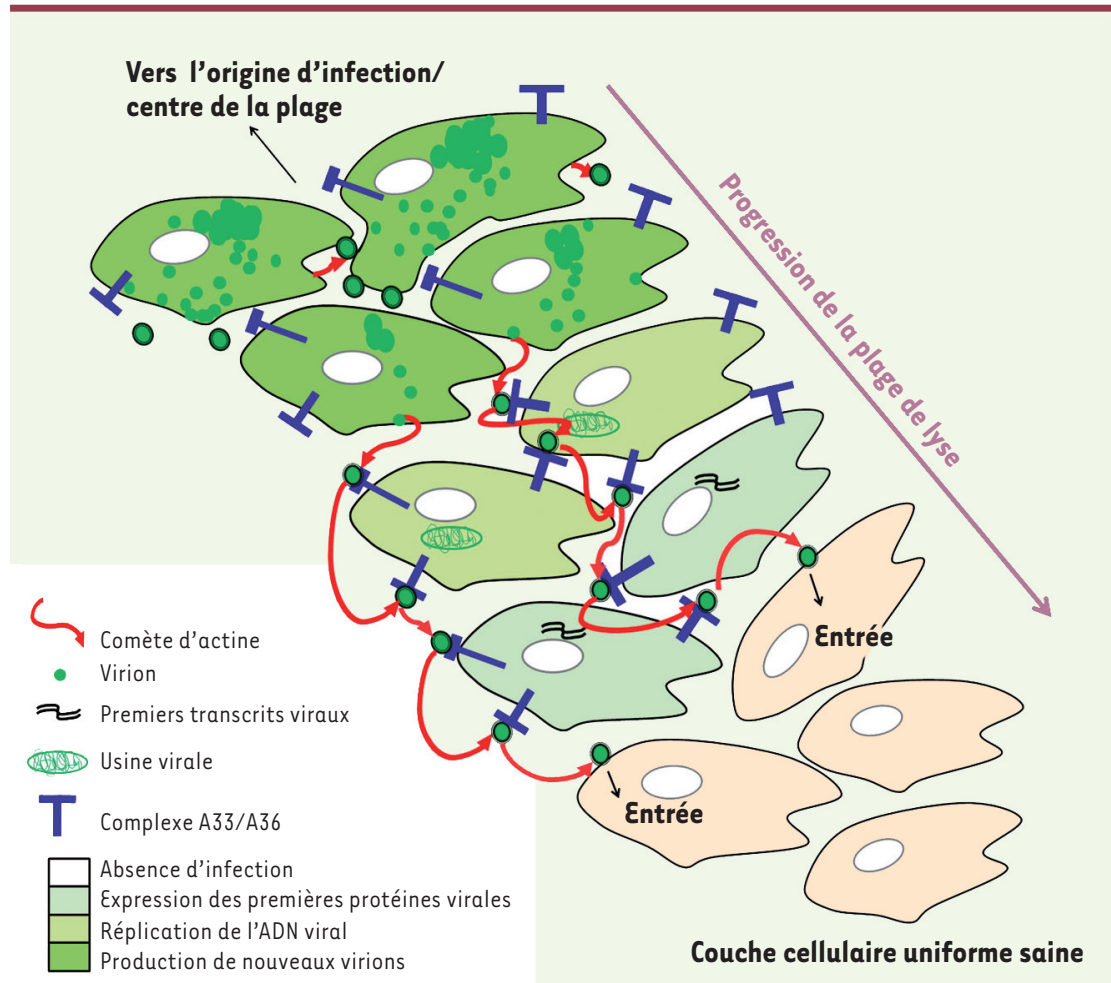

Figure 2. Modèle représentant la périphérie d'une plage de lyse formée par VACV et le mécanisme mis en œuvre par le virus pour se propager rapidement de cellule en cellule. Des virions produits par des cellules 5 à 6 heures après infection sont projetés par des comètes d'actine vers des cellules voisines. Si le virion entre en contact avec une cellule déjà infectée, exprimant le complexe A33/A36 à sa surface, une nouvelle comète d'actine est alors produite qui va repousser la particule virale vers d'autres cellules voisines. Le virion est alors catapulté de cellule infectée en cellule infectée jusqu'à ce qu'une cellule saine soit atteinte. Le virion est alors libre d'entrer et d'infecter cette cellule. Ce mécanisme de répulsion de particules super-infectantes explique que VACV se propage d'une cellule à une autre en moins de 2 heures.

va être de nouveau repoussé par une comète d'actine jusqu'à ce qu'il entre en contact avec une cellule qui n'est pas s'attacher et pénétrer. Ce catapultage de virions de cellules en cellules explique que le virus puisse se transmettre d'une cellule à une autre toutes les 1,2 heure.

\section{Une nouvelle cible}

pour des traitements antiviraux?

nismes qu'élabore VACV pour se propager rapidement de cellule en cellule est essentiel à la compréhension des pathologies liées à ce virus. D'autres virus

ches. 
comme herpes simplex de type 1 produisent également des plages de lyse dont la taille ne peut être expliquée seulement par leur cinétique de réplication. On peut donc penser que ces virus ont aussi développé des stratégies pour se transmettre d'une cellule à une autre à un stade précoce de l'infection en utilisant des mécanismes probablement différents de celui mis en œuvre par VACV. La compréhension de tels processus s'avère très prometteuse pour la découverte de nouvelles cibles thérapeutiques et la conception de nouveaux traitements antiviraux. L'élucidation de nombreuses stratégies développées par les virus pour optimiser leur propagation révèle leur complexité que nous sommes loin d'avoir décryptée complètement. Ces considérations peuvent même être élargies au monde bactérien puisque Listeria et Shigella se propagent aussi via la formation de comètes d'actine, de façon très similaire à VACV [8].

Les plages de lyse ont été mises en évidence il y a plus de 50 ans et ce n'est que très récemment qu'une étude plus approfondie des mécanismes de leur formation a révélé des propriétés virales inattendues. «Vingt fois sur le métier remettez votre ouvrage: polissez-le sans cesse et le repolissez...». $\diamond$

Rapid cell-to-cell spread:

a story of jumping viruses

\section{REMERCIEMENTS}

Les auteurs tiennent à remercier Alain Vanderplasschen pour ses commentaires sur le manuscrit et Medical Research Council pour son soutien financier.

\section{CONFLIT D'INTÉRÊTS}

Les auteurs déclarent n'avoir aucun conflit d'intérêts concernant les données publiées dans cet article.

\section{RÉFÉRENCES}

1. Dulbecco R. Production of plaques in monolayer tissue cultures by single particles of an animal virus. Proc Natl Acad Sci USA $1952 ; 38$ : 747-52.

2. Fenner F. Smallpox and its eradication. Geneva : World Health Organization, 1988.

3. Doceul V, Hollinshead M, van der Linden L, Smith GL. Repulsion of superinfecting virions: a mechanism for rapid virus spread. Science $2010 ; 327$ : 873-6.

4. Gaush CR, Smith TF. Replication and plaque assay of influenza virus in an established line of canine kidney cells. Appl Microbiol 1968; 16 : 588-94.

5. Harbour DA, Blyth WA, Hill TJ. Prostanglandins enhance spread of herpes simplex virus in cell cultures. J Gen Virol 1978; $41: 87-95$.

6. Payne LG, Kristenson K. Mechanism of vaccinia virus release and its specific inhibition by $\mathrm{Nl}$-isonicotinoyl-
N2-3-methyl-4-chlorobenzoylhydrazine. J Virol 1979; $32: 614-22$.

7. Stokes GV. High-voltage electron microscope study of the release of vaccinia virus from whole cells. J Virol $1976 ; 18: 636-43$

8. Cudmore S, Cossart P, Griffiths G, Way M. Actin-based motility of vaccinia virus. Nature $1995 ; 378: 636-8$.

9. Sanderson CM, Way M, Smith GL. Virus-induced cell motility. J Virol 1998; 72 : 1235-43.

10. Parkinson JE, Smith GL. Vaccinia virus gene A36R encodes a $M(r)$ 43-50 K protein on the surface of extracellular enveloped virus. Virology 1994 ; 204 : 376-90.

11. Roper RL, Wolffe $\varepsilon$ J, Weisberg A, Moss B. The envelope protein encoded by the A33R gene is required for formation of actin-containing microvilli and efficient cell-to-cell spread of vaccinia virus. J Virol 1998 ; $72: 4192-204$

12. Lorenzo MM, Galindo I, Griffiths G, Blasco R. Intracellular localization of vaccinia virus extracellular enveloped virus envelope proteins individually expressed using a Semliki forest virus replicon. J Virol $2000 ; 74: 10535-50$.

13. Roper RL, Payne LG, Moss B. Extracellular vaccinia virus envelope glycoprotein encoded by the A33R gene. J Virol 1996; $70: 3753-62$.

14. Röttger S, Frischknecht F, Reckmann I, et al. Interactions between vaccinia virus IEV membrane proteins and their roles in IEV assembly and actin tail formation. J Virol $1999 ; 73: 2863-75$.

15. Gurt I, Abdalrhman I, Katz $\varepsilon$. Pathogenicity and immunogenicity in mice of vaccinia viruses mutated in the viral envelope proteins A33R and B5R. Antiviral Res 2006 ; 69 : 158-64.

16. Thoulouze MI, Alcover A. Le «biofilm viral » : un nouveau mode de dissémination des virus? Med Sci (Paris) $2010 ; 26: 571-3$. 